\title{
APROPRIAÇÕES DO CANCIONEIRO DA AJUDA VERSUS RECEPÇÃO HISTÓRICA: \\ UMA CRÍTICA À UNIVERSALIZAÇÃO DA RESTITUTIO TEXTUS NAS ATUALIZAÇÕES DA EDIÇÃO MICHAELINA
}

\author{
Marinês de Jesus Rocha* \\ Marcello Moreira $^{* *}$
}

\begin{abstract}
RESUMO: Objetiva-se discutir as reiterações de critérios filológicos lachmannianos nas sucessivas edições e investigações sobre o Cancioneiro da Ajuda, tendo como base para a reflexão os dois volumes do manuscrito em questão, publicados por Carolina Michaelis de Vasconcellos, em 1904. Propõe-se aqui um confronto entre os pressupostos filológicos presentes nas contínuas apropriações da edição michaelina e as pesquisas sobre as formas de publicação iniciais da poesia galego-portuguesa, de cunho oral e performático, e, também, escribal. Desse modo, visa-se a demonstrar como a centralização dos estudos sobre trovadores e jograis objetivando-se a "restituição do texto", fundamentada esta na ideia de "autoria", em sua maioria, implica um rompimento do "costume" (consuetudo) relativo às formas iniciais de produção, circulação e recepção dessa poesia.
\end{abstract}

PALAVRAS-CHAVE: Cancioneiro da Ajuda; Edição michaelina; Recepção histórica; Restitutio textus.

\section{Introdução}

Para a produção de uma edição "crítica" e comentada do Cancioneiro da Ajuda, Carolina Michaelis procedeu ao elenco, de forma cronológica, de todos os autores de estudos relacionados direta ou indiretamente ao Manuscrito da Ajuda, perseguindo, sobretudo, questões referentes às corretas atribuições autorais e sobre as lições críticas conforme o códice original, ao tempo em que conhecia os apógrafos italianos. Desse modo, o estudo que aqui se lhes apresenta visa a demonstrar como a edição primeva do manuscrito da Ajuda constitui uma fonte de autoridade em relação às pesquisas subsequentes, ao predeterminar, para muitos estudiosos, o método, os objetivos e a função do estudo do Códice mencionado, como condição para que se produzissem considerações e comentários sobre o conjunto de cantigas galego-portuguesas.

Os princípios e os procedimentos adotados na monumental edição podem ser encontrados na Advertência Preliminar do primeiro volume, onde são expostas ainda as principais propostas de leitura operacionalizadas e o objetivo do trabalho empreendido e onde se afirma que serão utilizados os procedimentos "geralmente aceitos". Esse texto introdutório expõe muitas informações relevantes sobre o processo que precedeu a edição, embora se saiba que a exposição dos critérios críticos utilizados pela erudita fica mais clara no

\footnotetext{
* Doutora em Memória: Linguagem e Sociedade pela Universidade Estadual do Sudoeste da Bahia (Uesb). Durante o doutorado, foi Bolsista da Coordenação de Aperfeiçoamento de Pessoal de Nível Superior (Capes). ** Doutor em Literatura Brasileira pela Universidade de São Paulo (Usp). Professor Pleno da Universidade Estadual do Sudoeste da Bahia (Uesb).
} 
segundo volume, sobretudo, na Recensão bibliográfica dos principais estudiosos que trataram do manuscrito em questão ou contribuíram, com seus estudos e descobertas, para a elucidação de questões diversas. Esse estudo inicial revela a análise produzida pela filóloga em relação à qualidade e profundidade de cada uma das contribuições e, sobretudo, a respeito das questões de autoria, pelas quais ela afirma se interessar e que direcionam a "restituição" de cada uma das cantigas.

Para Ramos (2015), D. Carolina introduz o método germânico de edição em Portugal, sobretudo, com as edições de Sá de Miranda, cuja variedade de materiais e variantes autorais permitiu a "depuração" das versões genuínas do poeta; de Camões, com o intuito de separar, em meio às inúmeras obras que lhe foram atribuídas, aquelas que de fato lhe pertenciam, e do Cancioneiro da Ajuda, em que a estudiosa visa a restabelecer as cantigas galegoportuguesas conforme o original e identificar e atribuir corretamente cada canção.

No percurso metodológico seguido por D. Carolina, as noções de "variante" e "erro" são fundamentais, já que ambos os conceitos "teriam de estar omnipresentes na busca das fontes e na fixação do texto mais fiável” (RAMOS, 2015, p. 87). A metodologia aplicada aos textos galego-portugueses se vincula às noções então em voga no país de origem da erudita, de "restituir" a forma genuína dos textos, embora o método lachmanniano não seja citado em suas edições. A questão de não se mencionar o método subjacente à edição está ligada ao estado do manuscrito ajudense, que implicava maiores dificuldades para o estabelecimento crítico do texto, já que o material, fragmentário, tornava o trabalho complexo. A ausência do nome "Lachmann" não implica crítica à metodologia e aos critérios e categorias por ele formulados, antes o contrário, pois a finalidade da erudita alemã é a "restituição das cantigas".

Dessa maneira, os interesses apontados pela primeira estudiosa dos manuscritos galego-portugueses, como desvendar os autores dos poemas e fixar o "texto" do Cancioneiro da Ajuda, para a sua correta compreensão pelos portugueses nele interessados, que se tornou um princípio para as pesquisas subsequentes, colidem com estudos hoje considerados imprescindíveis sobre a "poética mediévica", que falam do caráter oral e movente da poesia dos trovadores e jograis, caráter esse que não foi objeto de escrutínio por parte dos filólogos oitocentistas e de muitos daqueles que mais tarde os seguiram. Os estudos do século XX, que intentaram recompor o costume poético da lírica de trovadores e jograis, centrada na voz e na performance, possibilitaram uma crítica à naturalização de conceitos críticos e procedimentos metodológicos lachmannianos, naturalização essa presente, por exemplo, em edições "críticas", resenhas e comentários textuais, incluindo-se entre eles a edição 
michaelina do Manuscrito da Ajuda, em que há o uso a-histórico de noções românticas como as de "origem" e "autoria". Entre os resultados de pesquisa mais significantes em que se produziu uma crítica à supracitada naturalização dessas categorias, como já anteriormente mencionado, estão os livros e artigos de Paul Zumthor, dos filólogos ligados a New Philology, e, entre nós, os de Moreira (2011, entre outros). Nesse sentido, os equívocos relacionados à crença na imutabilidade dos procedimentos metodológicos lachmannianos, que foram, inicialmente, utilizados em publicações como a edição "crítica" e "comentada" do Cancioneiro da Ajuda, estão relacionados à inobservância dos aspectos histórico-bibliográficos do Códice da Ajuda, como um todo, e da relação entre a manuscritura e a poética da vOz própria dos séculos XII a XIV, como afirma Moreira (2011). E os problemas relativos a não observação da parte codicológica dos antigos manuscritos se vinculam à crença de que materiais como estes estavam "à espera de publicação" (MOREIRA, 2011, p.291), desconsiderando-se a prática oral e escribal que explica sua compilação manuscrita e compartilhamento no Medievo. O estudioso em questão afirma que "como nossas noções de 'autoria' 'obra' e 'direito autoral' são fundamentais na determinação das relações que o leitor pode estabelecer com o texto literário, a não vigência de tais noções nos séculos XI, XII, XIII e depois, por exemplo, poderia implicar formas distintas de socialização e fruição da poesia” (MOREIRA, 2011, p. 135). No entanto, as considerações da filóloga sobre o modo como as cantigas presentes no Códice foram entendidas desde a sua descoberta e ao longo do tempo e foram também levadas ao público nelas interessado, tornaram-se fontes de autoridade para diversos estudos sobre as cantigas dos trovadores e jograis.

Dessa forma, o estudo aqui apresentado objetiva demonstrar os efeitos da aplicação da ideia de restitutio textus nos estudos sobre o Manuscrito da Ajuda, a partir da edição primeva desse Cancioneiro, publicada por Carolina Michaelis de Vasconcellos, em 1904, uma vez que esta edição impactou os diversos estudos sobre as cantigas galego-portuguesas dos pesquisadores que se lhe seguiram quanto aos procedimentos críticos a serem utilizados nas investigações de manuscritos e à finalidade dos estudos filológicos frente a tais objetos.

Visa-se, portanto, traçar um paralelo entre essas investigações e aquelas que implicam a sua historicização e crítica, porque evidenciam o modo histórico de existência das poesias dos trovadores e jograis.

\section{A restitutio textus do manuscrito da Ajuda}

Os textos introdutórios aos dois volumes da edição michaelina e as demais investigações a respeito dessa publicação evidenciam a finalidade do minucioso trabalho de se fixar 
criticamente o texto do manuscrito ajudense conforme o original. E a ideia da publicação do Cancioneiro da Ajuda surgiu a partir do interesse da filóloga pelo conjunto de cantigas que o compõem, desde 1877, uma vez constatada a presença de erros e deturpações nas edições anteriores, consideradas incompletas. Já a edição veio a público pelo contato mantido com Ernesto Monaci, com quem D. Carolina trocava correspondências e discussões a respeito do manuscrito, contato mantido também com Max Niemeyer, conforme nos afirma a própria erudita e que também constitui uma informação presente nos estudos de Castro (2004), Cunha (2004) e Ramos (2008).

A partir dessa ideia inicial, a estudiosa se dedicou com afinco ao conjunto de textos manuscritos em questão para publicá-lo, como se sabe, em uma edição "crítica” e comentada, tendo como referência, para a restituição das cantigas, os apógrafos italianos, a partir do momento em que teve notícia do Cancioneiro Colloci-Brancuti'. Sendo assim, na exposição desse percurso de análise minuciosa do Cancioneiro, torna-se clara a preocupação com "restituição do texto", já que havia partes do objeto apropriado que estavam "deturpadas", cujas edições anteriores não conseguiram corrigi-lo de forma satisfatória. Assim sendo, o objetivo de apresentar as cantigas do manuscrito em questão devidamente restituídas também se evidencia no glossário do Cancioneiro, publicado em 1920, em que a estudiosa avalia sua própria edição no que diz respeito à reconstituição textual de todas as canções que comporiam o Cancioneiro Geral Galego-português.

Os procedimentos metodológicos adotados na edição michaelina se vinculam às correspondências com o original e também ao confronto com os apógrafos italianos, fundamentais na identificação dos autores das poesias, como anteriormente mencionado. Desse modo, são centrais, na publicação, as noções de "originalidade" e de "correta atribuição autoral":

Publico as poesias integralmente, na mesma ordem em que estão no Códice da Ajuda, numerando-as e apontando o lugar que ocupam na edição baralhada de Varnhagen. Rejisto todas as lacunas. Tento determinar as suas dimensões, assim como o conteúdo provável das folhas arrancadas. Preencho-as pelo confronto crítico com os apógrafos italianos (em XVIII Secções do Apêndice). D' essas fontes tirei também os nomes dos autores (VASCONCELLOS, 1904, p. XI).

\footnotetext{
1 Para Castro (2004), D. Carolina teve interesse especialmente no modo como esse manuscrito poderia ser fundamental para a correta atribuição autoral do Cancioneiro da Ajuda: "A reacção global de D. Carolina a estas descobertas é bastante tépida. O que mais aprecia é a atribuição de autorias que os apógrafos italianos permitem, acabando com o anonimato geral dos poemas da Ajuda. Quando aos resultados das colações que começavam a ser possíveis entre os textos, relativizava-os assim: «É facto que o subsidio de variantes não é abundante e que essas ajudam pouco a melhorar e esclarecer textos tão bem conservados como os do antigo pergaminho da Ajuda» (CA, II: 53)" (CASTRO, 2004, p. 5)
} 
No exame detalhado das cantigas do Ajuda, em sua confrontação com as cópias italianas, as variantes foram identificadas e anotadas e aparecem na edição de 1904, exceto as canções figuradas apenas nos apógrafos. Para a filóloga, as correções de lições consideradas “deturpações” devem levar em consideração o contexto de sua cópia e o modo como os manuscritos foram feitos, como critérios pertinentes de exame daquilo que aparece como "lições divergentes". No entanto, Segundo Cunha (2004):

[...] nos textos conservados dos trovadores galego-portugueses, devemos ver não somente a existência de variantes, atribuíveis aos copistas, mas, principalmente, de variação, provocada por performances diversas de uma poesia que se difundiu durante um século e meio sob a forma cantada (CUNHA, 2004, p. 78).

As informações sobre a existência de variação nessa poesia, subministradas por Cunha (2004), são relevantes, apesar de, no estudo citado, o filólogo afirmar que uma edição das poesias galego-portuguesas deve se pautar na aproximação máxima com o original (Hansen \& Moreira, 2013, p. 68), o que parece ser uma justaposição de posturas crítica irreconciliáveis. Além da anotação das "lições divergentes" das cantigas, foram também realizadas alterações na ortografia, com o intuito de tornar o texto acessível a um número maior de interessados, sem que as características "arcaicas" do mesmo fossem desconsideradas. Por conseguinte, é elucidativa a afirmação da estudiosa de que teria realizado a "restituição" de todas as cantigas do manuscrito e as apresentaria em uma edição paleográfica e não "crítica", se pudesse reiniciar o trabalho em questão:

\footnotetext{
Se hoje recomeçasse, seguia outro rumo. Há muito que reconheci quanto melhor teria sido dar logo em 1880 a edição paleográfica para fazer corpo com os outros dois Cancioneiros; levar a eito numa Quarta Parte a restituição integral dos textos todos, logo que Ernesto Mónaci nos tivesse revelado as variantes do Cancioneiro Colocci- Brancuti e o estudo prometido. - Outros dois volumes independentes, um com o Dicionário e a Gramática, outro com Investigações Histórico - Literárias teriam completado a obra, quer fosse como Quinta e Sexta Parte da publicação Hallense, se o editor não estivesse demasiadamente desiludido, quer fosse em Portugal, por determinação da Academia Real das Ciéncias. Assim, saía melhor ordenada e completa. Custaria, porém, ainda mais anos de vida! (VASCONCELLOS, 1904, p. VII).
}

Dentre os critérios da edição michaelina, está a preservação das características da escrita dos trovadores galego-portugueses, pois, para a alemã, essas particularidades se afiguram relevantes no contexto histórico de produção do Cancioneiro. Desse modo, há uma seção, nessa edição primeva, referente à fala dos trovadores e a sua linguagem, em que se desenvolvem considerações sobre o português e o galego-português, tratando-se da conjugação dos verbos, do uso de vogais e semivogais, dentre outros temas relacionados à escritura das cantigas arcaicas em questão. No que diz respeito aos aspectos linguísticos, Vasconcellos (1904) operacionalizou intervenções relativas à escrita do texto, além disso, houve modificações no desenvolvimento de abreviaturas, na separação de "vocábulos conglomerados", nas 
mudanças da pontuação das canções e outros tipos de mudanças relativas, por exemplo, ao uso de algumas letras. Como Moreira (2011) nos faz entender em seu estudo do corpus poético atribuído a Gregório de Matos e Guerra, quando critica alguns filólogos lachmannianos, era prática comum no Oitocentos não haver menção à importância dos elementos propriamente bibliográficos dos manuscritos estudados quando se objetivava levar a efeito uma edição crítica qualquer, uma vez que a filologia oitocentista centrava-se no entendimento do "texto", no sentido dos "códigos linguísticos".

Dessa maneira, no segundo volume da edição crítica do Cancioneiro da Ajuda, a filóloga apresenta uma Resenha Bibliográfica, na qual, inicialmente, expõe uma descrição do códice que leva a público, seguida de uma análise crítica e cronológica dos escritos daqueles que, anteriormente a ela, se dedicaram ao Cancioneiro, sobretudo da primeira edição do Cancioneiro, feita em 1823 e impressa a pedido de Charles Stuart ${ }^{2}$. O percurso de investigações precedentes à edição michaelina, exaustivamente descrito, evidencia a importância de cada uma das edições anteriormente propostas e dos estudos escrutinados pela filóloga alemã, para a composição de uma das mais importantes edições do Ajuda, vinculada à "restituição" das cantigas nele contidas. Tal percurso de investigações foi sumariado por Castro (2004) e por Ramos (2008), como continuação dos estudos críticos, sócio-históricos, paleográficos e filológicos do Manuscrito em questão e reiteram a importância de alguns dos preceitos aplicados nessa edição primeva.

É possível notar, ao longo da detalhada revisão bibliográfica, a realização de uma leitura atenta, pela erudita, das contribuições de filólogos e historiadores da literatura portuguesa para a recolha de informações que se referem à autoria das cantigas do manuscrito em questão e também para a produção de comentários às edições anteriores no que se refere à fidelidade aos originais copiados. Dessa maneira, os esforços de estudiosos como D. Carolina estiveram sempre relacionados à escrita dos manuscritos, em detrimento do modo primeiro de existência oralizada que os caracterizou, embora as características dessa poesia não fossem desconhecidas dos filólogos que as investigaram inicialmente, como afirma Cunha (2004):

“O texto oral exige uma interpretação, que é também movente”. De uma maneira
geral, porém, os estudiosos da lírica trovadoresca, presos à letra dos cancioneiros,
tratam-na como uma poesia escrita. A própria advertência - aliás óbvia - que

${ }^{2}$ De acordo com Ivo Castro (2004): “Charles Stuart (1779-1845) foi um diplomata britânico que participou na reconstrução dos governos peninsulares após as guerras napoleónicas; encarregado de negócios em Madrid (1808) e enviado em Portugal (1810), aqui permaneceu até 1814, tendo sido um dos três membros do Conselho de Regência. Estes encargos não o impediram de se interessar pelo volume que tinha acoplados o cancioneiro e o Nobiliário de D. Pedro e que ainda repousava no Colégio dos Nobres, enquanto a Academia Real das Ciências se afadigava em ver como o havia de publicar" (CASTRO, 2004, p. 2) 
costumam fazer de que nela música e letra estavam interligadas não lhes tem permitido tirar maiores ilações. (CUNHA, 2004, p. 77)

Por conseguinte, a primeira problemática de que trata a erudita alemã, nas considerações que acompanham sua edição, é a questão autoral do conjunto de poesias, que gerou, desde cedo, muitas divergências entre os estudiosos, levando-os a modificar suas posições, conforme novos escritos surgiam. Em contrapartida, as pesquisas zumthorianas permitem uma crítica a essas edições e esboços críticos, produzidos no Oitocentos, que visam a tratar de atribuições autorais de textos manuscritos, como, por exemplo, o Cancioneiro da Ajuda, uma vez que o sentido de "autoria", no século XIX, é distinto daquele vigente ao tempo do circuito de produção, circulação e recepção das cantigas.

Dando continuidade ao estudo da edição michaelina, o surgimento de novas informações multiplicou as considerações a respeito do manuscrito, permitindo a análise de artigos, comentários, notas etc., de muitos autores, pela estudiosa, anteriormente à apresentação do texto crítico. A primeira edição do manuscrito da Ajuda, produzida em 1823, é um raro documento, fundamental para a proposta de fixação crítica, no entanto, D. Carolina afirma que o copista cometeu erros no processo de cópia, sendo necessária uma nova publicação que realize as devidas correções, já que o resultado dessa edição não foi satisfatório, pois falhou em relação à fidedignidade, sendo uma edição diplomática. Nesse sentido, os problemas relacionados à fidelidade e incompletude das edições anteriores justificam a necessidade de uma nova edição que constitua uma base segura de onde partirão os novos pesquisadores.

D. Carolina critica o modo como os primeiros estudiosos do Ajuda defenderam a ideia de que as poesias nele contidas foram compostas por um único autor, expondo como o avanço nas investigações e a descoberta das cópias italianas desmistificaram essa ideia. Dentre os estudiosos que, inicialmente, assim pensaram, destaca Adolfo Varnhagen, pelos estudos e pelas edições do manuscrito da Ajuda e, sobretudo, do códice Vaticano, que foram fundamentais no desenvolvimento de sua edição, bem como na convicção de que havia mais de um autor do conjunto de cantigas. As avaliações produzidas na edição michaelina, não apenas do trabalho do brasileiro mencionado, têm vínculo com o que afirmaram a respeito da atribuição autoral do conjunto de cantigas, pois, como anteriormente exposto, a identificação dos autores constituiu um dos objetivos de suas pesquisas para a publicação do Ajuda.

À vista disso, Zumthor (1993) afirma que a preocupação com a propriedade autoral de cada uma das canções herdadas de períodos tão distantes, que caracteriza os estudos produzidos nos séculos XIX e XX, por exemplo, se contrapõe ao contexto primeiro de partilha dessas poesias, fundado na "proliferação de variantes", cuja identificação de autoria, tal como compreendida séculos depois, não constituía uma questão de primeira ordem: 


\begin{abstract}
Invocar o anonimato de um texto ou de uma melodia não é constatar a simples ausência de um nome, porém uma ignorância enorme a este respeito. Por isto, a performance jamais é anônima. A ignorância realmente tem duas causas: ou bem a densidade e a opacidade de uma duração, ou ainda a dispersão numérica, quando parece que várias pessoas atualizaram sucessivamente os elementos da obra. Mas não há anonimato absoluto. Certamente o auditório, em geral, não se preocupa com o autor daquilo que ele ouve. Esta indiferença não implica que ele negue sua existência, mesmo que ela seja mítica. Mesmo nas sociedades mais tradicionais, o executante sabe bem que a questão virá cedo ou tarde: de onde foi tirado isto? A questão sempre fará sentido. A exatidão da resposta pouco importa (ZUMTHOR, 1997, p. 223).
\end{abstract}

Partindo de uma outra perspectiva, relacionada à "origem" e à "necessidade" de se atribuir apropriadamente cada canção trovadoresca do manuscrito ajudense, a erudita alemã escrutinou os três cancioneiros anteriormente mencionados, demonstrando "erros", no caso das cópias italianas, quanto à fidelidade aos originais e à restituição das cantigas. Nesse caso, por exemplo, a edição diplomática do Cancioneiro da Vaticana, de Ernesto Monaci, foi analisada em comparação à edição crítica do mesmo manuscrito, produzida por Teófilo Braga: aquela considerada perfeita em todos os critérios adotados, esta insuficiente na correspondência com o texto que sobreviveu e quanto à reconstituição das cantigas. Em relação aos estudos de Teófilo Braga, como em relação aos demais pesquisadores portugueses e estrangeiros, a erudita alemã se preocupa com as contribuições relativas à autoria das poesias contidas nos manuscritos que colacionou em sua edição e, para além disso, expõe os 'erros" cometidos tanto nas leituras de "vidas" de poetas quanto no que se refere às lições de alguns versos.

Prosseguindo com a análise dos autores que estudaram o Cancioneiro da Ajuda, para D. Carolina as inúmeras contribuições críticas permitem formular novas conjecturas sobre o modo de existência primitivo das canções e a respeito do modo como os três Cancioneiros se relacionavam quando de sua composição, cujo intuito é explicar, de forma adequada, o problema da multiplicidade de variantes textuais e a origem dos textos antigos. Nesse sentido, a descoberta do Colocci Brancuti teve impacto no que diz respeito à autoria do Cancioneiro da Ajuda, com a nomeação de dezessete dos seus autores. Sendo assim, esse é o cenário apresentado pela estudiosa portuguesa como o lugar de onde partiu para realizar a primeira edição do Cancioneiro da Ajuda, a partir da confrontação com as cópias italianas, destacando-se a identificação dos autores a partir do manuscrito mencionado.

O que se depreende da leitura dos textos introdutórios aos dois volumes da edição de Carolina Michaelis, nos quais a erudita alemã realizou o cruzamento de informações de vários estudiosos para falar da autenticidade e da autoria das canções, ao mencionar todas as investigações das quais teve notícias e sobre as quais se debruçou para realizar contrapontos ou 
para fundamentar posições críticas, é que constituem uma fonte de autoridade para muitos dos estudiosos que se the seguiram. A apropriação do estudo em questão permitiu que muitos pesquisadores tratassem da origem dos "textos", da autenticidade e dos supostos autores do conjunto de poesias antigas. Essa edição tem sido citada em diversas investigações sobre os cancioneiros medievais a partir da apropriação de noções filológicas que deveriam constituir a história da crítica textual, já que tais estudos possuem características que incorrem na desmaterialização dos “artefatos bibliográficos”, uma vez que a análise produzida incide apenas na inteligência da parte linguística dos manuscritos.

\section{Apropriação de lugares comuns críticos da edição michaelina}

Muitos pesquisadores seguiram os preceitos críticos da edição michaelina, sem, no entanto, haver mudança no que diz respeito à função da investigação filológica, assentada na busca pela correta atribuição autoral das cantigas e na restituição de textos originais e, isso, com base em apógrafos. Os fins da atividade crítica e os procedimentos considerados pertinentes, pela primeira filóloga da língua portuguesa, para a publicação impressa do Cancioneiro mencionado, portanto, se repetem em investigações as mais diversas.

Os preceitos lachmannianos, tal como instituídos na edição primeva do Ajuda, constituíram a base, por exemplo, da edição das cantigas de D. Joan Garcia de Guilhade, em 1907, por Oskar Nobiling. Assim sendo, a edição em questão parte de noções como a de "individualidade do poeta", para se avaliar a correta atribuição de cada uma das cantigas. Nesse caso, poesia e vida do autor são vinculadas, no texto introdutório da edição, a partir de informações subministradas na edição de Carolina Michaelis:

\footnotetext{
Nas duas tencĩes que possuimos de Guilhade, é elle proprio o aggressor, e o aggredido o jogral Lourenço, que, conforme se conclue da segunda dellas ( $\left.\mathrm{n}^{\circ} 38\right)$, estava ao seu serviço, cantando e acompanhando as suas cantigas e recebendo, a trôco disso, o sustento. Impossível é dizer hoje se eram justificadas as queixas que ahi trocam o amo e o criado. A censura que Guilhade dirige ao jogral (v. 750) por fazer mal sua parte da tenção, refere-se, como observa C. Michaelis, á infração da regra que prescrevia a correspondencia das rimas [...] (NOBILING, 1907, p. 4).
}

Joaquim José Nunes dedicou-se ao estudo e edição das cantigas trovadorescas de amor e de amigo a partir das contribuições da erudita alemã. A proposta interpretativa das cantigas de amigo, por exemplo, se pauta na busca por informações biográficas supostamente presentes nos versos atribuídos a cada trovador. Como evidencia a seção de seu livro, intitulada “notas autobiográficas, colhidas nas próprias cantigas", (Nunes, 1973) compreende as cantigas como confissões dos trovadores, constituintes, portanto, do "vivido" de cada um, ou como um meio para recompor os dados da vida de outros. Dessa maneira, os poemas 
constituem uma fonte de dados sobre a vida e permitem constituir uma biografia. Na metodologia utilizada para dar inteligibilidade às cantigas e para expor o modo como compreende a produção e a partilha dessa poesia, afirma que:

\begin{abstract}
Da comparação entre o que se sabe da vida de alguns trovadores galego - portugueses e os seus cantares vê-se que êles por vezes aí se referiam às suas próprias pessoas. É o que vou mostrar, começando, pelos conhecidos e tomando por base apenas as cantigas de amigo, pelos mesmos compostas (NUNES, 1973, p. 165).
\end{abstract}

A finalidade das cantigas de amigo é evidenciar uma relação com o vivido, como afirma o estudioso, ao descrever os objetivos da análise das poesias a partir de seus supostos autores: "prosseguindo no mesmo caminho, passarei a procurar traços autobiográficos dos seus autores nas cantigas que alguns composeram, deixando para o fim aqueles que nelas nenhuns elementos nos subministram a tal respeito" (NUNES, 1973, p. 176). No texto introdutório de sua edição, especificamente na seção mencionada, aquela da recolha de dados biográficos nas cantigas, abundam exemplos do modo como o estudioso deduz de cada verso os passos dados pelos trovadores e os acontecimentos que, supostamente, explicam a composição de uma ou outra cantiga.

Um outro estudo, que ilustra a apropriação de conceitos e procedimentos metodológicos da edição michaelina, é a antologia da lírica galego- portuguesa, publicada por Gonçalves \& Ramos (1992), uma vez que parte do pressuposto de que a identificação de autores de cada uma das cantigas e a fixação de lições que estejam mais próximas do original são primordiais para o entendimento das canções. Para as estudiosas em questão, "a escolha de um texto de autoria e cronologia incertas como primeiro da antologia, insere-se, aliás, numa perspectiva 'pedagógica', obedecendo à intenção de alertar o leitor não especialista para uma série de problemas suscitados pelo estudo da poesia lírica galego portuguesa" (GONÇALVES \& RAMOS, 1992, p. 18). Desse modo, conceitos lachmannianos do fazer filológico, como a noção de arquétipo a ser "restituído", dirigem a importante publicação, já em sua quarta edição. Um exemplo da circularidade dos estudos sobre o Manuscrito da Ajuda, nesse caso, aparece no tópico "as relações de B e V com A e o problema do arquétipo", onde se afirma que

[...] não existe ainda unanimidade acerca de questões fundamentais postas pela transmissão da nossa lírica medieval. Sobre estes problemas e sobre história da cada um dos testemunhos, a sua estrutura e características próprias - cujo conhecimento é pressuposto para a restituição crítica dos textos - pode o leitor interessado consultar a bibliografia específica citada neste capítulo, a qual, naturalmente, remete, não raras vezes, para a grande summa de Carolina Michaëlis (o vol. II da sua ed. Do Cancioneiro da Ajuda). (GONÇALVES \& RAMOS, 1992, p. 35). 
A matriz oitocentista é seguida nos procedimentos metodológicos utilizados para a edição e publicação de algumas das cantigas consideradas representativas do que foi a lírica galego-portuguesa, o que implica a seleção de edições consideradas confiáveis em relação à “restituição das cantigas”. Já em seu estudo, Cunha (2004) corrobora a conjectura exposta por D. Carolina de que haveria um Cancioneiro Geral anterior, que contemplaria as cantigas presentes no CA, CV e no CBN. Embora esse estudioso tenha se dedicado a expor a importância da noção de movência e de oralidade para as canções que foram herdadas em manuscritos, o núcleo de sua investigação é a noção de origem e de reconstituição dos textos:

A tradição manuscrita da poesia dos trovadores galego-portugueses é, porém,
muito pobre em número de códices, sendo que dois deles, o $C B N$ e o $C V$, deri-
vam provavelmente de um mesmo antígrafo, donde serem em geral mínimas as
divergências que apresentam nos textos comuns. O $C A$ distingue-se dos códices
italianos quanto a certos aspectos gráficos, particularmente no que se refere à
transcrição das palatais $[\lambda]$ e [n], mas deles também não se estrema de modo sen-
sível quanto à forma poético-linguística (CUNHA, 2004, p.79).

O estudioso mencionado, desse modo, corrobora a afirmação michaelina de que uma edição das poesias galego-portuguesas deve se pautar na aproximação máxima com o original, sendo relevante a análise das condições e possiblidades de se reconstruir um Cancioneiro Geral que conteria as poesias presentes nos manuscritos da Ajuda, da Vaticana e da Biblioteca Nacional. Para o estudioso citado, "a forma adequada para a edição de códices desta natureza é a fac-similar, que nos apresenta o livro medieval em sua concreta realidade" (CUNHA, 2004, p.81). Entretanto, sabe-se que uma preferência dos filólogos tradicionais pelas edições fac-similares se justifica pela ideia de que o nível de interpretação seria menor em relação àquele de uma "edição crítica", sendo que os requisitos para a produção de uma edição como esta são maiores e, consequentemente, com uma edição como aquela se chegaria supostamente a um texto mais próximo do que teria sido o "original” (MOREIRA, 2011).

De igual modo, Leite de Vasconcellos (1929), que acompanhou o processo de estudos que deu origem ao CA de D. Carolina, como se evidencia em inúmeras correspondências trocadas com a erudita alemã, tratou da história e das funções da filologia a partir de lugares comuns presentes na edição michaelina. Segundo ele, a edição crítica e definitiva deve preceder quaisquer teorias que viessem a elucidar os manuscritos herdados do Medievo, sendo que esse tipo de edição é a condição essencial para que outros estudiosos possam se debruçar sobre o artefato antigo. Tal compreensão do trabalho filológico torna-se clara no texto que escreveu quando da aquisição do Colocii Brancuti pela biblioteca de Lisboa, uma vez que destaca a relevância do manuscrito em questão na edição do Cancioneiro da Ajuda, produzida por D. Carolina Michaëlis, e o modo como a aquisição é fundamental numa posterior edição 
crítica do Cancioneiro da Vaticana, partindo-se da comparação dos manuscritos, para que se possa compreender as poesias neles contidas:

\begin{abstract}
Embora, como disse, a parte especial esteja publicada, e a outra parte a conheçamos pelos restantes Cancioneiros, não pode fazer-se uma edição crítica do C. Vaticano, sem se examinarem as variantes que existem no códice agora adquirido. A parte comum ao Cancioneiro da Ajuda foi já, nesse sentido, aproveitada pela S. ra D. Carolina Michaëlis. As pessoas que tratam das literaturas perfuntòriamente, ou apenas consideram nelas o lado estético, sintético, social, psicológico, dão geralmente pouca atenção ao lado filológico, isto é, ao da exactidão formal do texto; mas é evidente que sem o texto apurado, ou crítico, em sentido filológico, mal podem construir-se teorias, e as que assim se constroem, ficam às vezes muito temerárias, para não dizer que se tornam inúteis [...] (VASCONCELLOS, 1929, p. 1134).
\end{abstract}

Para tornar clara a importância de que uma edição crítica seja precedente às conclusões sobre quaisquer tradições textuais, o filólogo português menciona os equívocos cometidos nas interpretações dos manuscritos antigos relacionados ao termo "d'elle dino"/ “de ledino", erro de leitura cometido por Teófilo Braga, que levou muitos estudiosos a investigarem um gênero que supostamente não existiu, no intuito de atestar como esse tipo de edição dos manuscritos antigos pode evitar certas conjecturas e afirmações errôneas, já que a fixação do "texto definitivo" assegura a "fidelidade" dos materiais de onde partem.

Para ele, o mais importante em um método filológico é a "restituição do texto", que exige de cada editor muito conhecimento da língua, para que o seu trabalho satisfaça a crítica e esteja de acordo com o conjunto de "textos" com o qual trabalha e para que os pesquisadores futuros tenham condições de propor com segurança novos estudos:

\footnotetext{
Um dos caracteres que distinguem o método da moderna Filologia românica é exactamente o da apurada ou crítica restituição dos textos. Não se empreende hoje uma edição séria, em parte alguma do mundo, que não obedeça àquele princípio; ela requer habitualmente muito saber e muito acume de espírito (VASCONCELLOS, 1929, p. 1135).
}

De forma semelhante, Castro (2004) produziu uma cronologia histórica das edições do Ajuda e fez importantes considerações a respeito das tradições galego-portuguesas. De acordo com o estudioso, a edição primeva do Ajuda é fundamental no que se refere às "origens" dessa poesia, assim como no estudo da pertença autoral de cada uma das cantigas dos trovadores. Já Ramos (2008) parte da edição de D. Carolina para tratar a "escrita" do dito Cancioneiro, concebendo-a como uma "autêntica reconstituição lachmanniana" (RAMOS, 2008, p. 3) das cantigas, primordial nos estudos a respeito dos trovadores e jograis e no estabelecimento das cantigas pertencentes a cada um deles: 
contrário. O recurso a potentes instrumentos de análise para a fenomenologia codicológica e para o modus operandi da reprodução textual em um único Cancioneiro tende, aqui, muito mais para a busca do profiling de uma diacronia e de um diassistema textual sob bases neolachmannianas no estudo da variantística e na acurada descrição crítica do zelo ou da displicência formal. Uma ampla recensio e uma ampla interpretatio, que confortará ou não o recurso último à emendatio, se temos presente a constatação de recensio aperta em alguns casos (RAMOS, 2008, p. 21/ grifos autorais).

A pesquisa em questão expõe uma quantidade significativa de dados a respeito tanto da escrita, letra e materiais utilizados para a inscrição do Cancioneiro, quanto do suporte material e sua historicidade, no entanto, o estudo desses aspectos está ligado à ideia de arquétipo e de construção de stemmata codicum que possam elucidar questões originais do Cancioneiro ajudense.

Os preceitos lachmannianos que definem a função dos estudos crítico-textuais foram também seguidos por Mongelli (2008), que, ao tratar do estado dos cancioneiros dos trovadores do Medievo, se apropria dos lugares comuns da filologia, fundados por estudiosos como D. Carolina, ao afirmar que:

É possível verificar o grave problema que representa para os pesquisadores o "estabelecimento do texto", com 'lições' tão divergentes entre si e às vezes tão desviadas dos originais, que se corre o risco de arquitetar uma interpretação baseada em falácias ou em comprometedores 'desvios' dos códices (MONGELLI, 2008, p. 2).

Conforme essa perspectiva filológica, a questão das “origens" da poesia galego-portuguesa é primacial, sendo indispensáveis os esforços de alguns estudiosos para a reconstituição do arquétipo do conjunto de poesias anteriormente mencionado, embora haja muitas dificuldades para a realização de tal tarefa.

\section{Considerações Finais}

A investigação sobre o Cancioneiro da Ajuda demonstra as inadequações do estudo de poesias dos trovadores e jograis a partir da atualização de conceitos e procedimentos metodológicos voltados para a fixação do texto crítico, no qual se apresenta, supostamente, o “texto" em conformidade com o original. Constata-se, desse modo, que muitos estudos filológicos voltados para as cantigas dos trovadores e jograis podem ser reunidos sob o denominador comum da naturalização de conceitos e procedimentos críticos. Essas investigações se pautam na noção de "origem" e em uma intervenção que se assenta na necessidade de se "restituir" às cantigas sua originalidade, livrando-as das diversas interferências de que foram alvo no processo de transmissão e compartilhamento e, conjuntamente, na busca por atribuições corretas das produções que nos chegaram em manuscritos, aos seus devidos autores, 
como comprovam alguns exemplos aqui apresentados. Assim, tendo em vista o impacto da edição de D. Carolina no estudo das cantigas em galego-português, seria conveniente aos novos estudos nortearem as análises crítico-textuais, sobre materiais que estão temporalmente muito distantes, pelas práticas e usos que ratificam a importância de se "compilar poemas e organizá-los e dispô-los no interior de códices poéticos nos séculos medievais" (MOREIRA, 2011, p. 298).

\section{APPROPRIATIONS OF CANCIONEIRO DA AJUDA VERSUS HISTORICAL RECEPTION: A CRITIQUE OF THE UNIVERSALIZATION OF RESTITUTIO TEXTUS IN THE UPDATES OF THE MICHAELINEAN EDITION}

ABSTRACT: Our aim is to discuss the reiterations of Lachmannian philological criteria in the successive editions and investigations on Cancioneiro da Ajuda, taking as a basis the analysis of the two volumes of the manuscript in question, published by Carolina Michaelis de Vasconcellos, in 1904. It is proposed here a confrontation between the philological assumptions present in the continuous appropriations of the michaelina edition and the research on the initial forms of publication of Galician-Portuguese poetry of oral, performative and, also, scribal nature. In this way, the objective is to demonstrate how the centralization of studies on troubadours and mistrels, aiming at "restitution of the text" based on the idea of "authorship" implies, in its majority, a rupture of the "custom" (consuetudo) concerning the initial forms of production, circulation and reception of this poetry.

KEYWORDS: Cancioneiro da Ajuda; Michaelinian Edition; Historical reception; Restitutio textus.

\section{REFERENCIAS}

CASTRO, Ivo. O Cancioneiro da Ajuda e suas edições. Página de Ivo Castro da FLUL/CLUL. Disponível em: http://www.clul.ulisboa.pt/files/ivo_castro/2004_edies_do_Canc._Aju da.pdf Acesso: 16/07/2017.

CUNHA, Celso. Significância e movência na poesia trovadoresca. In: Sob a pele das palavras. Rio de Janeiro: Nova Fronteira: Academia Brasileira de Letras, 2004, p. 69-98.

GONÇALVES, Elsa.; RAMOS, Maria Ana. A lírica galego-portuguesa (textos escolhidos). 4.ed. Lisboa: Editorial Comunicação, 1992.

HANSEN, João Adolfo \& MOREIRA, Marcello. Para que todos entendais: poesia atribuida a Gregório de Matos e Guerra: Letrados, Manuscritura, Retórica, autoria, obra e público na Bahia dos séculos XVII e XVIII, Volume 5 /João Adolfo Hansen, Marcello Moreira. Belo Horizonte: Autêntica Editora, 2013, Vol. 5.

MONGELLI, Lênia Márcia. Estudos interdisciplinares sobre o trovadorismo galaico- português. Série Estudos Medievais 1: Metodologias [recurso eletrônico] / Gladis Massini-Cagliari, Márcio Ricardo Coelho Muniz, Paulo Roberto Sodré, Risonete Batista de Souza organizadores. - Araraquara : ANPOLL, 2008. (Série Estudos Medievais; n. 1).

As fontes da lírica profana galego - portuguesa. Série Estudos Medievais 2: fontes [recurso eletrônico] / Gladis Massini-Cagliari, Márcio Ricardo Coelho Muniz, Paulo Roberto Sodré, organizadores. - Araraquara : ANPOLL, 2009. (Série Estudos Medievais ; n. 2). 
MOREIRA, Marcello. Critica Textualis in Caelum Revocata? Uma Proposta de Edição e Estudo da Tradição de Gregório de Matos e Guerra. São Paulo: Editora da Universidade de São Paulo, 2011.

NOBILING, O. As cantigas de D. Joan Garcia de Guilhade - Trovador do seculo XIII, Edição Critica, com Notas e Introdução. Erlangen: K.B. Hof - Und Univ. - Buchdruckerei Von Junge \& Sohn, 1907.

NUNES, J. Joaquim. Cantigas D'Amigo dos trovadores galego portugueses. Edição crítica acompanhada de introdução, comentário, variantes, e glossário (Vol. I-introdução). Lisboa: Centro do livro brasileiro, 1973.

RAMOS, Maria Ana. O Cancioneiro da Ajuda: confecção e escrita. Tese (Doutorado) - Departamento de línguística geral e românica, Lisboa, Universidade de Lisboa, Lisboa. 2008. Disponível em: https://Repositório.ul.pt/bitstream /10451/553/1/17066_o_cancioneiro_1.pdf Acesso: 03/01/2018

Carolina Michaëlis E A edição crítica. Entre arte e método. In: Carolina Michaëlis de Vasconcelos: uma homenagem [livro eletrônico]/organização: Valéria Gil Condé, Lênia Márcia Mongelli, Yara Franteschi Vieira. -São Paulo: NEHILP/FFLCH/USP, 2015, p. 67-100.

VASCONCELLOS, Carolina Michaelis de. Cancioneiro da Ajuda. Halle A. S., Max Niemeyer, (Vol I/Vol II), 1904.

Glossário do Cancioneiro da Ajuda. VASCONCELLOS, J. Leite de. Revista Lusitana - Archivo de Estudos Philologicos e Etnologicos relativos a Portugal. Vol XXIII. Lisboa: Livraria classica Editora de A. M.Teixeira, 1920, p. V-XII/ 1-95.

VASCONCELLOS, J. Leite de. A Filologia Portuguesa- Esboço Histórico. In: Opúsculos IV (Filologia Parte II) Coimbra: Imprensa da Universidade, 1929, pp. 841-919.

ZUMTHOR, Paul. A letra e a voz - a "literatura" medieval. São Paulo: Companhia das Letras, 1993.

. O Intérprete. In: Introdução à poesia oral. São Paulo: Hucitec/Educ, 1997, p. 221-240.

Recebido em: 14/10/2020.

Aprovado em: 30/12/2020. 